\title{
Views on contentious practices in dairy farming: The case of early cow-calf separation
}

\author{
B. A. Ventura, M. A. G. von Keyserlingk, C. A. Schuppli, and D. M. Weary ${ }^{1}$ \\ Animal Welfare Program, Faculty of Land and Food Systems, University of British Columbia, 2357 Main Mall, Vancouver V6T 1Z4, Canada
}

\begin{abstract}
The public has become increasingly interested in the welfare of food animals, but the food animal industries possess few mechanisms for public engagement. Here we present results from a web-based forum designed to allow stakeholders to share views on controversial issues in dairying. In response to the question "Should dairy calves be separated from the cow within the first few hours after birth?" participants were able to indicate "yes," "no," or "neutral" and either write a reason in support of their view or select reasons provided by other participants. Four independent groups of participants were recruited (a total of 163 people); 31\% said they had no involvement in the dairy industry; the remaining $69 \%$ (with some involvement in the industry) were students or teachers $(33 \%)$, animal advocates $(13 \%)$, producers $(11 \%)$, veterinarians $(9 \%)$ and other dairy industry professionals (3\%). Overall, little consensus existed among participants across groups; $44 \%$ chose "yes," 48\% "no," and 9\% "neutral." Responses varied with demographics, with opposition to early separation higher among females, animal advocates, and those with no involvement with the dairy industry. A fifth group was recruited at a dairy industry conference (an additional 28 participants); $46 \%$ chose "yes," $32 \%$ "no," and 21\% "neutral." Across all 5 groups, opponents and supporters often referenced similar issues in the reasons they provided. Opponents of early separation contended that it is emotionally stressful for the calf and cow, it compromises calf and cow health, it is unnatural, and the industry can and should accommodate cow-calf pairs. In contrast, supporters of early separation reasoned that emotional distress is minimized by separating before bonds develop, that it promotes calf and cow health, and that the industry is limited in its ability to accommodate cow-calf pairs. These results illustrate the potential of web-based forums to identify areas of agreement and conflict among stakeholders,
\end{abstract}

Received August 7, 2012.

Accepted May 16, 2013.

${ }^{1}$ Corresponding author: danweary@mail.ubc.ca providing a basis for the development of practices that address shared concerns.

Key words: animal welfare, producer attitude, maternal filial bond, public engagement

\section{INTRODUCTION}

Public interest in the welfare of farm animals continues to expand, making it increasingly important that those working with dairy cattle engage with the public on controversial issues related to animal care. The dairy industry has traditionally enjoyed a positive public image, but this may erode if practices are perceived to be out of step with societal expectations. Creating platforms for communication about contentious issues fosters engagement with, and interaction between, diverse industry stakeholders, including the public (Castle and Culver, 2006). We suggest that such engagement will help the dairy industry remain socially sustainable (Boogaard et al., 2008), that is, maintain good standing as an industry committed to fulfilling the public trust (Schweikhardt and Browne, 2001).

Animal welfare is conceptualized in different and sometimes overlapping ways (Fraser et al., 1997). For example, some people may especially value cow health or milk production as indicators of good welfare, whereas others may emphasize subjective experiences (such as pain and distress) or the ability to express natural behaviors. Much of the literature on attitudes about farm animal welfare originates from Europe and has focused on the views of people not involved in animal production (e.g., European Commission, 2007). The limited data available on North Americans (e.g., Prickett et al., 2010) also shows a high level of concern about farm animal issues. People's views toward animal welfare vary depending on a variety of factors, such as the species in question (Driscoll 1992), the animals' perceived cognitive capacity, and familiarity with the animal (Knight and Barnett, 2008), as well as family or personal experience with farm animals (Boogaard et al., 2006; Kendall et al. 2006). Nonindustry people often conceptualize good animal welfare largely in terms of the animals' living environment (e.g., abundant space and freedom to roam) but also in terms of health, including 
nutritional aspects (Harper and Henson, 2001; Frewer et al., 2005; Ellis et al., 2009). Notably, the naturalness of husbandry systems (in rearing systems, housing, and behavioral opportunities) is a dominant concern among people not involved in animal production (Te Velde et al., 2002; Lassen et al., 2006; Maria, 2006; Vanhonacker et al., 2008).

In contrast, naturalness has typically been shown to be a lower priority for those working within agriculture, who tend to instead emphasize concerns related to animal health (Te Velde et al., 2002; Vanhonacker et al., 2008), though this is not uniformly the case. For example, European organic livestock producers also view naturalness as an important component of animal care (Lund et al., 2004; Vetouli et al., 2012; Spooner et al., 2012). Moreover, approaches to animal welfare vary among individual producers (Vetouli et al., 2012) and producers are often aware of the diverse elements that affect farm animal welfare (Spooner et al., 2012).

Some European research has addressed views on issues specifically relevant to dairy cattle welfare (Boogaard et al., 2008, 2010; Ellis et al., 2009), but these works have focused on individuals not involved in agriculture; little information exists on attitudes of dairy producers and other dairy industry stakeholders. Moreover, with the exception of our previous study on tail docking (Weary et al., 2011), little work has been done on the views of North Americans on issues in dairy cattle welfare.

The aim of this paper was to examine the views of participants from within and outside the dairy cattle industry on the specific practice of separating the dairy calf from the dam at or soon after birth. This common management practice represents a particularly interesting case study for stakeholder engagement. In nature, a cow nurses the calf for months, weaning is gradual, and calves form strong bonds with their mother and with other cows and calves in the herd that can last for years (Kilgour and Dalton, 1984; Vitale et al., 1986). In contrast, most dairy farms separate the cow and calf within a few hours of birth, whereupon the cow re-enters the production cycle and the calf is placed in individual or group housing and fed milk artificially until weaning at 4 to 12 wk of age (von Keyserlingk and Weary, 2007). European research suggests that separation of the newborn dairy calf from its dam elicits concern from members of the public (Boogaard et al., 2010), but again, it is unclear how North Americans view this practice.

The goals of this paper are to (1) examine the views of participants from within and outside of the dairy industry on early separation of the cow from her calf, and (2) compare these views with the scientific literature on the advantages and disadvantages of the practice. This study is one component of the CowViews project (see Weary et al., 2012), designed to provide a forum for diverse stakeholders to air their views on issues within dairy production. One intended application of this approach is to help foster agreement among stakeholders on contentious practices.

\section{MATERIALS AND METHODS}

The current study used the same approach as an earlier study on tail docking (Weary et al., 2011). We hosted an online forum that presented several scenarios describing contentious practices in dairy production. Here we present the results of one of these scenarios: cow-calf separation. The forum was hosted on the YourViews site (http://www.yourviews.ubc.ca), designed to facilitate public engagement on ethical issues in science and technology (Ahmad et al., 2006). Our methodology used the N-Reasons platform (described in Danielson 2010), which collects both quantitative (responses to close-ended questions) and qualitative data (responses to open-ended questions). Knight and Barnett (2008) point out that qualitative approaches are particularly appropriate when examining people's attitudes toward animal use, especially when little is known about the topic in question (in this case, the range of views that exist around cow-calf separation). Incorporating a qualitative aspect also overcomes some of the issues associated with more traditional survey methods (Ahmad et al., 2006) by allowing participants to generate constructs beyond those conceived by the researchers (as discussed in Knight et al., 2003; Kalof et al., 2008).

In keeping with the typology of public engagement mechanisms put forward by Rowe and Frewer (2005), our approach is one of stakeholder consultation. More specifically, the engagement process described in this study is a form of electronic consultation, which involves the sending of a document - in this case, a link to an interactive website - to potential participants with the aim of obtaining "open responses on a significant issue" (Rowe and Frewer, 2005). This study was approved by the Behavioral Research Ethics Board at the University of British Columbia.

\section{Participant Recruitment}

Our intention was not to collect a random or representative sample of any specific population, but rather to include a diverse range of participants to increase our chances of achieving saturation in views. The forum was made available on the Internet so anyone with internet access could participate. To encourage participation of people in the North American dairy industry, we published brief articles in producer magazines (Progressive 
Dairyman and Ontario Farmer) that invited readers to participate.

Most participants entered the site between November 20, 2010, and August 11, 2011, and were randomly allocated to 1 of 4 independent groups (groups 1-4). This approach allowed us to evaluate potential differences between groups and minimize the chance that particularly compelling individuals could dominate an argument (Henrich and Gil White, 2001). In addition, we opportunistically recruited a fifth group of participants at the producer-oriented Western Canadian Dairy Seminar in Red Deer, Canada, between March 6 and 9, 2012, to increase representation of views from people within the dairy industry (group 5).

\section{Survey Design}

Demographic questions classified participants on the basis of sex, age, education level, and country of origin and of residence. Participants were asked to indicate their familiarity ("very familiar," "somewhat familiar," and "not familiar") with dairy production. They also specified if they had no involvement in the dairy industry (e.g., nonindustry stakeholders) or, if involved (e.g., industry stakeholders), the nature of their involvement ["farmer" (e.g., dairy farmer, operator or worker), "veterinarian," "student or teacher" (e.g., professor, instructor, or student in animal or veterinary science), "dairy industry professional" (e.g., dairy nutritionist, researcher, milking equipment dealer, livestock auction employee), or "animal advocate" (e.g., member of farm animal protection organization)].

To ensure that all participants had access to the same basic information, the following background on cow-calf separation was provided:

Dairy farmers often remove the calf from the cow within the first few hours of birth. This is done in response to several concerns, including the following: the calf may become infected from pathogens carried by the cow or her environment; the calf may become injured by the cow or the barn equipment; the calf will not be able to nurse from the cow and receive adequate colostrum (first milk produced by the cow after birth) and milk; the calf will drink too much milk, which increases the farmer's cost of feeding and increases the risk of diarrhea; allowing the cow and calf to bond will result in greater separation distress when separation does occur; farms are often not well designed for cow-calf pairs, so keeping cows and calves together can be considered an extra chore.
Others consider that some form of cow-calf contact is an important element of natural behavior, and believe that this contact is beneficial to the cow and calf. On these farms the cow and calf are kept together for days or even weeks after birth.

Participants were then asked "Should dairy calves be separated from the cow within the first few hours after birth?" and could respond "Yes, because...," "No, because....," or "Neutral, because...". Participants were able to explain their response in an open text box or select 1 or more of the reasons left by earlier participants. In this way, the number of yes, no, and neutral responses (quantitative data) was recorded along with the reasons for the responses (qualitative data). An added benefit to this approach is that it allowed participants to see and respond to reasons from other participants, providing participants the ability to reflect upon their own reasons within a quasi-social context (Danielson, 2010).

Reasons were displayed in a list format typical of user posts on a web forum. The number of reasons accumulated over time as new participants joined such that later participants could view a larger list of reasons than those available to early participants. Within each group, reasons were displayed on the page by popularity (according to votes) to inform participants about any emerging social consensus. In addition, more recent reasons were also displayed near the top to counter any primacy effect (following Danielson, 2010). Participants could select multiple reasons, but, for analysis, each selection was discounted by the total number of selections, such that each participant contributed a single vote (e.g., if a participant selected 2 reasons, 0.5 votes were allocated to each reason).

\section{Quantitative Analysis}

Chi-squared tests were used to test the effect of each demographic category on response (yes, no, neutral). This test requires that expected frequencies must be greater than 5 . In some cases this requirement was not met due to the low proportion of neutral votes; in these cases we reran the test after omitting neutral votes. In no case did this change the significance of the results presented below.

\section{Reason Analysis}

Content analysis was used to analyze participant reasons (following Coffey and Atkinson, 1996). We developed a coding scheme to understand the central themes 
of concern raised by participants, irrespective of participant demographics. This process began by reading all reasons and identifying issues (e.g., repercussions of calf not receiving enough milk) that could be assigned codes (e.g., calf nutrition). Reasons were then reread to check codes for consistency and altered slightly as a deeper understanding of the reasons emerged. Two of the authors (B. A. Ventura and C. A. Schuppli) conducted this first stage independently. They compared their codes to evaluate consistency; initial consistency was high. Where differences arose, coders discussed their interpretations until they reached a mutually consistent coding scheme consisting of main codes and subcodes, subsequently termed themes and subthemes.

The number of times that themes were referenced was counted. A theme was only counted once within each reason, regardless of how many times it was referenced within that reason. Because participants from different demographic groups often selected the same reason, the analysis focused primarily on how themes were used within each response category (yes, no, neutral) and not on how often demographic groups used certain themes in their reasons.

The voices of the participants are reflected in selected quotations that capture the essence of the participants' concerns for each theme. Each quotation is followed by the number of times that other participants voted for that reason. Because participants could select multiple reasons, some reasons acquired noninteger votes (e.g., 4.6 times).

\section{QUANTITATIVE RESULTS}

\section{Groups 1-4}

A total of 163 people participated in groups 1 to 4 $($ range $=38-43$ participants per group; Table 1$) ; 74 \%$ were female; $48 \%$ were between the ages of 19 and 29 and $21 \%$ were above the age of $50 ; 64 \%$ were from Canada and $21 \%$ from the United States; and $65 \%$ had attended a university with an additional $27 \%$ in possession of at least some graduate education. One-third of the participants were academics (students or teachers), $31 \%$ had no involvement with dairy farming, $13 \%$ were animal advocates, $11 \%$ farmers, $9 \%$ veterinarians, and $3 \%$ dairy industry professionals. Most respondents considered themselves either somewhat $(43 \%)$ or very (44\%) familiar with the dairy industry.

Overall, 44\% supported early separation (chose "yes"), $48 \%$ were opposed (chose "no"), and $9 \%$ were "neutral" (Table 1). Participant decisions varied with sex $\left(\chi^{2}=\right.$ $22.7, \mathrm{df}=2, P<0.0001)$, age $\left(\chi^{2}=15.7, \mathrm{df}=4, P\right.$ $=0.0034)$, education $\left(\chi^{2}=10.7\right.$, df $\left.=4, P=0.0303\right)$, nationality $\left(\chi^{2}=14.7, \mathrm{df}=4, P=0.0054\right)$, involvement $\left(\chi^{2}=74.4, \mathrm{df}=10, P<0.0001\right)$, and familiarity $\left(\chi^{2}=32.8, \mathrm{df}=4, P<0.0001\right)$ with the dairy industry (Table 1). For example, support for early separation was higher among males, people in their 20s, people with graduate education, and participants originating from the United States. Participants who described themselves as animal advocates or with no involvement with the dairy industry were less supportive of early separation than veterinarians, students and teachers, farmers and dairy professionals. Support for early separation was highest among participants who considered themselves very familiar with dairy production.

Most (87\%) participants chose only 1 reason in support of their views (Table 1). Participants who selected multiple reasons were always consistent in their yes, no, or neutral responses (i.e., chose either all supporting or all opposing reasons). Within each group (1-4), participants were fairly evenly split between yes and no decisions (Table 1), with no differences in vote choice between groups $\left(\chi^{2}=9.5, \mathrm{df}=6, \mathrm{~ns}\right)$.

\section{Group 5}

Respondents in this group $(\mathrm{n}=28)$ were mostly male $(64 \%)$ and affiliated with the industry (e.g., $52 \%$ farmers and industry professionals; see Table 2 for more demographic information). Although the overall level of support for early separation in this group was similar to groups 1 to 4, more neutral responses were observed (and consequently fewer opposing responses; Table 2).

\section{QUALITATIVE RESULTS AND DISCUSSION}

\section{Group Differences}

The creation of separate groups allowed us to evaluate consistency in the results across the groups. Although groups differed in participant demographics, they were similar with respect to the number of reasons, the distribution of votes, and the major themes. Similarity across diverse groups suggests that these themes would likely also emerge in other samples of participants. In addition, similarity in themes across groups suggests that particularly compelling reasons voiced within a group did not lead to idiosyncratic outcomes.

Participants in groups 1 to 4 provided a total of 46 reasons (10-13 reasons per group) averaging 52 words in length (range $=2-211$ ). Group 5 participants provided 17 reasons averaging 58 words in length (range $=$ 17 to 144). Votes were split similarly within each of the groups, and all groups contributed reasons in support of all major themes identified. 
Table 1. The number and percentage of participants (groups $1-4, \mathrm{n}=163$ ) who supported ("yes"), opposed ("no"), and were "neutral" to the practice of early separation of the dairy cow and calf ${ }^{1}$

\begin{tabular}{|c|c|c|c|c|}
\hline Item & $\mathrm{n}$ & Yes $(\%)$ & No $(\%)$ & Neutral $(\%)^{2}$ \\
\hline Total participants & 163 & 43.6 & 47.9 & 8.6 \\
\hline \multicolumn{5}{|l|}{ Sex } \\
\hline Female & 117 & 31.6 & 57.3 & 11.1 \\
\hline Male & 42 & 73.8 & 23.8 & 2.4 \\
\hline \multicolumn{5}{|l|}{ Age } \\
\hline $19-29$ & 77 & 55.8 & 33.8 & 10.4 \\
\hline $30-49$ & 50 & 32.0 & 56.0 & 12.0 \\
\hline$\geq 50$ & 34 & 32.4 & 67.7 & 0.0 \\
\hline \multicolumn{5}{|l|}{ Country of origin } \\
\hline Canada & 102 & 32.4 & 56.9 & 10.8 \\
\hline United States & 34 & 67.7 & 26.5 & 5.9 \\
\hline Other & 24 & 54.2 & 41.7 & 4.2 \\
\hline \multicolumn{5}{|l|}{ Dairy background } \\
\hline Farmer & 18 & 61.1 & 33.3 & 5.6 \\
\hline Veterinarian & 15 & 100.0 & 0.0 & 0.0 \\
\hline Student or teacher & 54 & 63.0 & 22.2 & 14.8 \\
\hline Dairy professional & 5 & 60.0 & 40.0 & 0.0 \\
\hline Animal advocate & 21 & 4.8 & 95.2 & 0.0 \\
\hline No involvement & 50 & 14.0 & 76.0 & 10.0 \\
\hline \multicolumn{5}{|l|}{ Familiarity } \\
\hline Very familiar & 72 & 68.1 & 29.2 & 2.8 \\
\hline Somewhat familiar & 70 & 24.3 & 61.4 & 14.3 \\
\hline Not familiar & 21 & 23.8 & 66.7 & 9.5 \\
\hline \multicolumn{5}{|l|}{ Responses } \\
\hline Single & 142 & 45.8 & 45.8 & 8.5 \\
\hline Multiple & 21 & 28.6 & 61.9 & 9.5 \\
\hline \multicolumn{5}{|l|}{ Group } \\
\hline 1 & 39 & 38.5 & 56.4 & 5.1 \\
\hline 2 & 43 & 41.9 & 55.8 & 2.3 \\
\hline 3 & 38 & 39.5 & 47.4 & 13.2 \\
\hline 4 & 43 & 53.5 & 32.6 & 14.0 \\
\hline
\end{tabular}

${ }^{1}$ Responses are sorted by demographic categories, by those who provided a single versus multiple responses, and by replicate discussion group (groups 1-4). Categories with fewer than 163 responses resulted if some participants did not provide demographic information.

${ }^{2}$ Percentages have been rounded to the nearest decimal point. As a result, the summation of percent yes, no, and neutral responses within each row may not always equal 100.0

\section{Themes}

Participants raised the following themes (in order of popularity): cow and calf emotions, calf health, cow health and production, a natural life, dissatisfaction with industry motivations, and the changeability of dairy farming structure (Table 3). Many of these themes incorporated 1 of the following aspects of animal welfare (Fraser et al., 1997): biological functioning (calf health, cow health and productivity), subjective experience (cow and calf emotions), and the role of nature (a natural life). Cow and calf emotions, calf health, cow health and production, and changeability of dairy farming structure were common themes among all types of responses; thus, although opponents and supporters reached opposing conclusions, they often referenced similar issues in defending their stance (Table 3).

1. Cow and Calf Emotions. The most common theme was emotional repercussions for the cow and calf as a result of separation. Three subthemes were identi- fied: a general awareness that cows and calves have an emotional life, reference to the bond between cow and calf, and concern about how severing that bond would result in distress.

Opponents of early separation suggested that cows have feelings and that cows and calves enjoy being together (e.g., "she has ... [an] emotional investment in the calf [4.6]"). This concern was also echoed in a neutral response, "It seems like an awful thing to have to do and I would ultimately prefer that we recognized the cows as sentient beings... [1]." Opponents also reasoned that "cows benefit by forming a bond with their calf... [12.3]." The idea of severing the bond provoked strong reactions, in part because the cow-calf bond was seen as similar to the human mother-child relationship. This can be seen in the use of language such as, "divorcing or orphanage-type management [16.5]," and, "[the] cow, being a mother, is supposed to have an emotional string attached to her calf ... by no means having a lesser degree of recognition compared to a human mother [7.6]." 
Table 2. The number and percentage of industry-targeted participants (group $5, \mathrm{n}=28$ ) who supported ("yes"), opposed ("no"), and were "neutral" to the practice of early separation of the dairy cow and calf

\begin{tabular}{|c|c|c|c|c|}
\hline Item & $\mathrm{n}$ & Yes $(\%)$ & No $(\%)$ & Neutral $(\%)^{2}$ \\
\hline Total participants & 28 & 46.4 & 32.1 & 21.4 \\
\hline \multicolumn{5}{|l|}{ Sex } \\
\hline Female & 9 & 22.2 & 55.6 & 22.2 \\
\hline Male & 16 & 56.3 & 18.8 & 25.0 \\
\hline \multicolumn{5}{|l|}{ Age } \\
\hline $19-29$ & 8 & 37.5 & 25.0 & 37.5 \\
\hline $30-49$ & 15 & 40.0 & 40.0 & 20.0 \\
\hline$>50$ & 2 & 100.0 & 0.0 & 0.0 \\
\hline \multicolumn{5}{|l|}{ Country of origin } \\
\hline Canada & 20 & 45.0 & 30.0 & 25.0 \\
\hline United states & 3 & 66.7 & 0.0 & 33.3 \\
\hline Other & 5 & 40.0 & 60.0 & 0.0 \\
\hline \multicolumn{5}{|l|}{ Dairy background } \\
\hline Farmer & 11 & 63.6 & 18.2 & 18.2 \\
\hline Veterinarian & 1 & 100.0 & 0.0 & 0.0 \\
\hline Student or teacher & 5 & 0.0 & 60.0 & 40.0 \\
\hline Dairy professional & 3 & 33.3 & 33.3 & 33.3 \\
\hline Animal advocate & 3 & 0.0 & 66.7 & 33.3 \\
\hline No involvement & 4 & 100.0 & 0.0 & 0.0 \\
\hline \multicolumn{5}{|l|}{ Familiarity } \\
\hline Very familiar & 17 & 52.9 & 23.5 & 23.5 \\
\hline Somewhat familiar & 8 & 37.5 & 37.5 & 25.0 \\
\hline Not familiar & 2 & 50.0 & 50.0 & 0 \\
\hline
\end{tabular}

${ }^{1}$ Responses are sorted by demographic categories. Categories with fewer than 28 responses resulted from some participants not providing demographic information.

${ }^{2}$ Percentages have been rounded to the nearest decimal point. As a result, the summation of percent yes, no, and neutral responses within each row may not equal 100.0.

Opponents also viewed separation as stressful, as seen in statements such as, "Immediate separation [would] cause a grievous, trauma-like situation for both [7.6]."

Supporters of early separation also voiced concern about the emotional bond and acknowledged that separation distress was "an important welfare issue [10.8]." However, supporters often viewed separation as inevitable and separation distress as more serious the longer cow and calf stayed together. Many pointed out that "it's better for both the calf and the mom to separate sooner because otherwise there is too much attachment, and it's very hard on the mother! [12]" This view is consistent with scientific literature showing that the cowcalf bond develops rapidly and strengthens over time (as reviewed in Flower and Weary, 2003), such that cow and calf distress responses escalate when separation is delayed (after $4 \mathrm{~d}$ vs. $6 \mathrm{~h}$ and $1 \mathrm{~d}$, Weary and Chua, 2000; after 2 wk vs. 1 d, Flower and Weary, 2001). However, little research to investigate the positive emotional effects of prolonged contact has been done, which poses challenges to meaningful harm-benefit analyses of emotional repercussions of separation.

2. Calf Health. Concerns about calf disease, nutrition (colostrum and milk access), and injury were common. Supporters of early separation tended to believe that physical separation protected the health of the calf, for example, stating, "Research has shown it benefits calf health [17.3]." Another supporter suggested that "the calf can be relocated to a clean housing facility where it will not be exposed to the various diseases commonly found in maternity areas [2]." This relocation was valued in part because of the individual care made possible, but more importantly because it provided a "means to break disease transmission [6.5]," with reduction in Johne's disease (Mycobacterium avium ssp. paratuberculosis) most often mentioned.

Opponents to early separation expressed skepticism that early separation reduced disease in calves. For example, a popular reason suggested that early separation "does not work in preventing disease; current methods of management still result in high levels of disease in dairy calves [12.3]." It is unclear from the comments whether opponents believed calf health could be effectively managed if calves were not separated from their dams or if they did not consider these claims sufficient to justify early separation in light of other perceived risks to cow and calf welfare.

Disagreement was also observed on whether early separation was effective in meeting the calf's needs for colostrum and milk. Supporters believed that early separation made it easier to deliver and monitor colostrum intake (e.g., "There is no way to monitor for adequate colostrum intake if the calf nurses freely [3.3]"). Other supporters worried about the repercussions of feeding 
Table 3. Reason themes and subthemes used by participants who either opposed, supported, or were neutral about early separation of the dairy cow from her calf ${ }^{1}$

\begin{tabular}{|c|c|c|c|c|c|}
\hline Theme & Subthemes & Description & Used by & Reasons $^{2}$ & Votes $^{3}$ \\
\hline Cow and calf emotions & Emotional life; cow-calf bond; stress & $\begin{array}{l}\text { Awareness of the emotional lives of cows and } \\
\text { calves; references to their bond; concerns about } \\
\text { how severing the bond could create stress. }\end{array}$ & $\begin{array}{l}\text { Opponents, } \\
\text { supporters, neutrals }\end{array}$ & 16 & 83.85 \\
\hline Calf health & Health; nutrition; physical safety & $\begin{array}{l}\text { Beliefs about whether early separation promotes } \\
\text { or threatens calf's ability to minimize disease } \\
\text { risk; obtain adequate colostrum or milk; and } \\
\text { avoid injury. }\end{array}$ & $\begin{array}{l}\text { Opponents, } \\
\text { supporters, neutrals }\end{array}$ & 22 & 83.4 \\
\hline $\begin{array}{l}\text { Dairy cow health and } \\
\text { production }\end{array}$ & Health; production & $\begin{array}{l}\text { Beliefs about whether early separation promotes } \\
\text { or threatens cow's health (especially udder } \\
\text { health); efficiency and maximization of milk } \\
\text { production. }\end{array}$ & $\begin{array}{l}\text { Opponents, } \\
\text { supporters, neutrals }\end{array}$ & 11 & 51.9 \\
\hline A natural life & Reverence for nature; natural behavior & $\begin{array}{l}\text { Belief that nature is a guide in evaluating the } \\
\text { animals' best interest; concerns about ability to } \\
\text { express natural behaviors. }\end{array}$ & Opponents, neutrals & 8 & 40.9 \\
\hline $\begin{array}{l}\text { Dissatisfaction with industry } \\
\text { motivations }\end{array}$ & Dishonesty; wrong focus; profit motive & $\begin{array}{l}\text { Disapproval with goals and motivations of } \\
\text { producers; beliefs that industry focuses on profit } \\
\text { and convenience over animal welfare. }\end{array}$ & Opponents & 8 & 37.55 \\
\hline $\begin{array}{l}\text { Changeability of dairy } \\
\text { farming structure }\end{array}$ & Farm design; cost burden & $\begin{array}{l}\text { Belief that farms can or should change to } \\
\text { accommodate cow-calf pairs. Supporters } \\
\text { often accepted status quo as best minimizing } \\
\text { consequences in an unchangeable system; } \\
\text { opponent demands often supplemented with } \\
\text { suggestions to shift cost burden to consumers. }\end{array}$ & $\begin{array}{l}\text { Opponents, } \\
\text { supporters, neutrals }\end{array}$ & 12 & 34.3 \\
\hline
\end{tabular}


the calf if separation is delayed: "It's hard to feed the calf after they get used to feeding from the mom [12]," or, "A cow would hold her milk ... and her calf cannot drink what a cow has in her udder [4]." Conversely, opponents reasoned, "Calves benefit from the care they receive from the cow (e.g., by better access to milk and colostrum)...[12.3]." One opponent suggested an economic incentive for allowing the calf to nurse: "The cow produces colostrum which isn't commercially saleable and the calf should have free access to this for the first couple of days at least [1.3]."

Literature supports both the opponent and supporter's perspectives on calf health. Cow-calf contact appears to confer many benefits for calf health (European Food Safety Authority, 2006); it has been shown that cows stimulate calves and encourage earlier meconium expulsion and better digestive function (Metz and Metz, 1986), and that calves show improved colostrum absorption (Selman et al., 1970), fewer bouts of scours (Weary and Chua, 2000), and BW gains if they are kept with the cow (Metz, 1987; Flower and Weary, 2001). More generally, several studies report lower morbidity and mortality among nursing calves than among separated calves; several factors, including milk quality and quantity, could account for these differences (Webster et al., 1985; Rajala and Castrén, 1995; Krohn, 2001). In contrast, other work suggests a harmful effect of prolonged contact: calves in these studies were at greater risk for failed passive transfer (Wesselink et al., 1999), diarrhea (Svensson et al., 2003), and infection by the bacterium responsible for Johne's disease (Marcé et al., 2011). As Rushen et al. (2008) note, it is difficult to distinguish if effects on calf health are attributable to the act of separation itself or to subsequent housing and management. Regardless of whether or not the calf is with the mother, it is critical to ensure adequate colostrum intake and hygiene (Frank and Kaneene, 1993; Vasseur et al., 2010).

3. Cow Health and Production. Participants were also concerned about udder health and milk production. Supporters of early separation expressed concerns about the lack of milk letdown causing health problems for the cow. For example, some suggested, "The farmers then have to use oxytocin on the cow to force her milk to come out... Cows can get very sick if they don't release their milk [4]." Early separation was also believed to reduce the risk of "teats [being] scraped or damaged due to sucking... [1.3]."

In contrast, opponents believed the calf's presence to be beneficial to the cow's health and noted that "frequent suckling [helps to] prevent mastitis and metritis [12.3]," as well as milk fever. Others appeared to attribute health benefits to the cow having avoided the emotional distress of separation, as exemplified by the comment: "It is worth consideration as to how much adverse effect this emotional trauma can cause to the physical, medical, and biological health and efficiency of the mother in terms of giving milk [7.6]." Or, as another participant put it, "Allowing the cow to be with her calf certainly keeps her happy and content. I believe a happy cow produces more milk [1.5]."

In this case, the available scientific literature tends to support opponents: suckling has been reported to decrease the cow's retention of fetal membranes (Krohn et al., 1990) and has a positive effect on udder health, often through the reduction of mastitis (Krohn et al., 1990, 1999; as reviewed in Krohn, 2001). Further, overall milk yield is not reduced by the presence of calves (Metz, 1987; Flower and Weary, 2001), implying that cows can maintain high production and enjoy the health benefits associated with suckling. Whether positive health effects are also attributable to the cow's improved emotional health is less clear. We were unable to find any evidence to address the claim that suckling is a meaningful risk for teat damage.

4. A Natural Life. Opponents often cited their desire for a more natural life for animals either because of inherent benefits of nature, or because a natural state has instrumental benefits in performance of natural behaviors. Many opponents held the general belief that cow-calf pairs were what nature intended. For example, a prevalent view was that "nature tells us the cow is born to enjoy the companionship of her calf for a certain time and vice versa... [16.5]." Hence, opponents rejected early separation in part because it "is not natural [12.3]." Another reason suggested that early separation would hinder the development and expression of natural behaviors in the calf:

"As cattle are social animals, the establishment
of socialization behaviors - for example, licking
and/or grooming and the self-confidence toward
socialization-starts at early life of the animals,
and, thus, those calves separated early from their
mothers are believed to have low socialization and
[are] more stressed when mixed later with group-
mates in a pen. Lastly ... the suckling behavior,
which has a great impact on the entire life of the
calf, would be hijacked by the early cow-calf sepa-
ration [16.5]."

Opponent views on this theme are in keeping with the Farm Animal Welfare Council's (1997) recommendation for dairy cattle to be kept in environments permissive of natural behaviors. It is clear that systems that allow the calf to be kept with the dam, even for a restricted amount of time, allow expression of natural maternal behaviors (reviewed by Krohn, 2001). Maternal rear- 
ing also has important consequences for the calf's later social skills, as the dam is an important social model for the calf (Howery et al., 1997; Krohn et al., 1999; Flower and Weary, 2001). For example, calves raised with the dam show decreased fear of new conspecifics (with 4 d of maternal contact; Krohn et al., 1999) and interact more with other calves (with 2 wk of contact; Flower and Weary, 2001).

5. Dissatisfaction with Industry Motivations. Some opponents of early separation also expressed dissatisfaction with what they perceived to be the dairy industry's motivations. For example, some viewed dairy production as wrongly prioritizing practicality or productivity over animal welfare (e.g., "I think early cowcalf separation is practiced for the purpose of reducing labor management of the owner, not for the cow-calf wellbeing [16.5]"). Others maintained that any extra effort required did not sway their opposition: "I know that keeping the cow and calf together [means] extra work for the producers. But I prefer the option of weaning the calf slowly, thinking [of] the welfare of both the calf and cow [5]." One reason contextualized the practice of early separation as a symptom of a larger problem: "Our entire system of agriculture is designed around productivity, and we've lost track of what's important [1.6]."

Some opponents considered early separation to be unacceptable because it is a profit-driven practice, a view evident from language such as, "To treat a cow as simply a money-maker is callous [4.6]," or, "[These are] excuses to exploit the animals for money [2.8]." One respondent asked, "Why can't farmers treat the very thing that makes them so much money with some respect? [0.5]," suggesting a moral obligation to provide cows with a good life in return for their provision of milk and meat (Rollin, 2010; Janzen, 2011).

6. Changeability of Dairy Farming Systems. Finally, beliefs about whether dairy farms could or should change to accommodate cow-calf pairs shaped some participants' views on separation. Some supporters tended to situate the issue within the larger context of current production systems, where early separation was the only feasible solution:

“... [continued contact] is probably impossible to implement in most dairies. Dairy farms in Canada and the United States would have a severe limitation of space, proper housing for cows and calves to stay together, feeding systems, and labor in order to try such a change.... In this case, the change would probably lead to another problem. Looking at the big picture from an entire dairy operation point of view, removing the calf soon after birth is currently the practice that best minimizes the possible negative consequences [10.8]."

This view seemed to resonate with some neutral respondents who appeared unable to decide between the perceived benefits of separation and impracticality of cow-calf pairs: "Given the present circumstances of society and intensive agriculture, I don't think it is possible.... On the other hand [if evidence shows benefits for the calf] ... farming units should be built to accommodate these two together [1]."

In contrast, opponents were more likely to believe that dairy systems could be changed to accommodate both producer and animal needs. One reason suggested, "Consideration should be made into farm design that accommodates both the cow-calf relationship and production efficiency [2.3]." A few neutral participants also reasoned, "If most of the problems around leaving the cow and calf together are a matter of environment, why not change the environment? [3]"

\section{GENERAL DISCUSSION}

This study used an online platform that enabled diverse stakeholders to share their views on the issue of cow-calf separation. One advantage of our approach is that it provides a rapid, practical, and cost-effective way of reaching and collecting information from diverse groups (Danielson, 2010). Likewise, our use of mixed stakeholder groups may overcome some of the hurdles (such as cost and organizational barriers) related to carrying out face-to-face town hall meetings or focus groups. Though we collected quantitative data, our results cannot be considered representative on a regional or national scale, nor should our results be extrapolated to predict participants' behavior as consumers or as citizens. Rather, by combining quantitative and qualitative response options, we obtained results that gave us a sense of the level of contention generated by the issue of cow-calf separation along with the reasoning behind these diverse views.

It should also be noted that the platform did not require participants to directly engage with responses from previous participants. Although many participants selected reasons authored by others, showing some level of engagement, some likely ignored the arguments of others and simply entered their own response. Another potential limitation of our approach is that we provided more background information in favor of early separation than against, and this difference may have biased participant responses in favor of support. We also acknowledge that the mere provision of background information may have primed or constrained participants. 
However, participants introduced new issues (e.g., the health of the cow), suggesting that the provision of the background was not limiting. We encourage future work to consider a range of engagement methods, but suggest that our online approach of collecting open-ended responses from multiple stakeholders was effective in describing a variety of themes relevant to views on this topic.

We recruited participants within and outside of the dairy industry. It was beyond our aim to fully explain differences between the stakeholder groups who took part in our study, but the inclusion of the fifth group (consisting primarily of individuals closely connected to the dairy industry) provides some insight into how views differ between industry and nonindustry stakeholders. Producers have a valuable perspective on the practices that prompt ethical debates in farming (Driessen, 2012), and those in our sample often showed nuanced reasoning in relating how they decided on their current practice. For instance, one producer acknowledged, "I end up varying quite a bit on when I pull calves. I falter on whether it's more beneficial for the calf to get that initial contact with the cow...[1]." Another suggested, "Ideally you would separate them physically but not visually for 24 hours (and then remove the calf) ... if they could be in close proximity, but not physical contact, then that would help the cow in her transition... [1]." These comments illustrate how producers are well positioned to formulate creative methods of management that address the competing concerns.

Participants with close ties to the dairy industry and who expressed their support of early separation also tended to evaluate the practice within the larger context of the industry and viewed this issue as one of many issues to balance. In contrast, some of our nonindustry participants may have been less able to see the big picture, perhaps because they had little understanding of the complexity of farming or were unwilling to make some trade-offs that supporters believed were required. Further work is needed to better understand how the connection to and knowledge of the dairy industry influences views on such practices, but it is worth noting that perspectives from outside the dairy industry have an important role to play in the development of socially sustainable practices (Boogaard et al., 2008). By bringing industry and nonindustry stakeholders together into a common forum, engagement efforts such as the one described here serve as a feedback mechanism and highlight areas of disagreement that policy makers may need to address. For example, it appears that emotional distress and calf health are critical areas of concern around cow-calf separation; policy that addresses only one concern at the expense of the other is likely to be ill received, at least by some stakeholders. Ultimately, a balanced discussion that takes into account multiple perspectives is required to avoid conflict (Callon et al., 2009).

A key finding from the current study was that participants on both sides of the issue raised similar concerns. For example, both opponents and supporters of early separation expressed concern for the calf's wellbeing, suggesting opportunities for compromise. One participant's comment suggested that some concerns around early separation could be mitigated if management was changed for calves after separation: "My bigger issue is that calves not be housed individually after separation, and that proper management skills be in place to make sure that calf health and nutrition is not compromised [4]." This type of suggestion highlights areas of compromise that might be implemented more rapidly; social housing in small groups can meet many of the calf's social needs (De Paula Vieira et al., 2010, 2012) without necessarily compromising health (Losinger and Heinrichs, 1997; Hänninen et al., 2003). Providing social housing for calves would not address all the issues mentioned above, but would likely be considered a step in the right direction by some of the opponents in our study.

Finally, we also compared views expressed by our participants to the scientific research on cow-calf separation, as policy makers often turn to science to address social concerns about animal production. In some situations, disagreements on contentious issues can be resolved by applying appropriate scientific research (Croney et al., 2012). For example, Weary et al. (2011) found that supporters of tail docking often expressed the belief that this practice improved udder health and cleanliness despite abundant scientific evidence showing no such benefit (see Sutherland and Tucker, 2011); better communication of this scientific evidence could help inform a change in practice in keeping with societal concerns. In the case of cow-calf separation, the available science is less clear and, in some cases, contradictory. Resolving this issue will no doubt require more research in determining when and how separation is best achieved. However, it seems unlikely that science alone can bridge the gaps identified in the current study, in part because disagreements are rooted in value differences among participants (Croney et al., 2012). Scientific efforts that address one type of concern are unlikely to be considered persuasive by participants who prioritize other issues.

\section{ACKNOWLEDGMENTS}

We thank Peter Danielson and the Norms Evolving in Response to Dilemmas (NERD) group at the University of British Columbia (UBC) for support in develop- 
ing the YourViews platform, and E. Ormandy and J. Huzzey (also from UBC) for their helpful comments on the manuscript. We are especially grateful to the many participants who shared their views.

\section{REFERENCES}

Ahmad, R., J. Bailey, G. Bornik, P. Danielson, H. Dowlatabadi, E. Levy, and H. Longstaff. 2006. A web-based instrument to model social norms: NERD design and results. Integr. Assess. J. 6:9-36.

Boogaard, B. K., B. B. Bock, S. J. Oosting, and E. Krogh. 2010. Visiting a farm: An exploratory study of the social construction of animal farming in Norway and the Netherlands based on sensory perception. Int. J. Sociol. Agric. Food 17:24-50.

Boogaard, B. K., S. J. Oosting, and B. B. Bock. 2006. Elements of societal perception of farm animal welfare: A quantitative study in the Netherlands. Livest. Sci. 104:13-22.

Boogaard, B. K., S. J. Oosting, and B. B. Bock. 2008. Defining sustainability as a socio-cultural concept: Citizen panels visiting dairy farms in the Netherlands. Livest. Sci. 117:24-33.

Callon, M., P. Lascoumes, and Y. Barthe. 2009. Acting in an Uncertain World: An Essay on Technical Democracy. MiT Press, London, UK.

Castle, D., and K. Culver. 2006. Public engagement, public consultation, innovation and the market. Integr. Assess. J. 6:137-152.

Coffey, A., and P. Atkinson. 1996. Concepts and coding. Pages 26-53 in Making Sense of Qualitative Data: Complementary Research Strategies, A Coffey and P. Atkinson, ed. Sage, Thousand Oaks, CA.

Croney, C. C., M. Apley, J. L. Capper, J. A. Mench, and S. Priest. 2012. The ethical food movement: What does it mean for the role of science and scientists in current debates about animal agriculture? J. Anim. Sci. 90:1570-1582.

Danielson, P. 2010. Designing a machine to learn about the ethics of robotics: The N-reasons platform. Ethics Inf. Technol. http:// dx.doi.org/10.1007/s10676-009-9214-x.

De Paula Vieira, A., M. A. G. von Keyserlingk, and D. M. Weary. 2010. Effects of pair versus single housing on performance and behavior of dairy calves before and after weaning from milk. J. Dairy Sci. 93:3079-3085.

De Paula Vieira, A., M. A. G. von Keyserlingk, and D. M. Weary. 2012. Presence of an older weaned companion influences feeding behavior and improves performance of dairy calves before and after weaning from milk. J. Dairy Sci. 95:3218-3224.

Driessen, C. 2012. Farmers engaged in deliberative practices: An ethnographic exploration of the mosaic of concerns in livestock agriculture. J. Agric. Environ. Ethics http://dx.doi.org/10.1007/ s10806-010-9293-z.

Driscoll, J. W. 1992. Attitudes toward animal use. Anthrozoos 5:3239.

Ellis, K. A., K. Billington, B. McNeil, and D. E. F. McKeegan. 2009. Public opinion on UK milk marketing and dairy cow welfare. Anim. Welf. 18:267-282.

European Commission. 2007. Attitudes of EU citizens toward animal welfare. Special Eurobarometer 270. Wave 66.1. TNS Opinion and Social. Accessed Jan. 23, 2012. http://ec.europa.eu/public_ opinion/archives/ebs/ebs_270_en.pdf.

European Food Safety Authority. 2006. The risks of poor welfare in intensive calf farming systems. An update of the Scientific Veterinary Committee Report on the Welfare of Calves. EFSA-Q-2005-014. European Food Safety Authority. Parma, Italy.

Farm Animal Welfare Council. 1997. Report on the Welfare of Dairy Cattle. Farm Animal Welfare Council, Surbiton, UK.

Flower, F. C., and D. M. Weary. 2001. Effects of early separation on the dairy cow and calf. II: Separation at 1 day and 2 weeks after birth. Appl. Anim. Behav. Sci. 70:275-284.

Flower, F. C., and D. M. Weary. 2003. The effects of early separation on the dairy cow and calf. Anim. Welf. 12:339-348.
Frank, N. A., and J. N. Kaneene. 1993. Management risk factors associated with calf diarrhea in Michigan dairy herds. J. Dairy Sci. 76:1313-1323.

Fraser, D., D. M. Weary, E. A. Pajor, and B. N. Milligan. 1997. A scientific conception of animal welfare that reflects ethical concerns. Anim. Welf. 6:187-205.

Frewer, L. J., A. Kole, S. M. A. Van De Kroon, and C. De Lauwere. 2005. Consumer attitudes toward the development of animalfriendly husbandry systems. J. Agric. Environ. Ethics 18:345-367.

Hänninen, L., H. Hepola, J. Rushen, A. M. de Passillé, P. Pursiainen, V.-M. Tuure, L. Syrjälä-Qvist, M. Pyykkönen, and H. Saloniemi. 2003. Resting behaviour, growth and diarrhoea incidence rate of young dairy calves housed individually or in groups in warm or cold buildings. Acta Agric. Scand. A Anim. Sci. 53:21-28.

Harper, G., and S. Henson. 2001. Consumer concerns about animal welfare and the impact on food choice. EU FAIR CT98-3678 Final Report. Accessed Jun. 12, 2013. http://ec.europa.eu/food/animal/ welfare/eu_fair_project_en.pdf.

Henrich, J., and F. J. Gil White. 2001. The evolution of prestige Freely conferred deference as a mechanism for enhancing the benefits of cultural transmission. Evol. Hum. Behav. 22:165-196.

Howery, L. D., F. D. Provenza, R. E. Banner, and C. B. Scott. 1997. Social and environmental factors influence cattle distribution on rangeland. Appl. Anim. Behav. Sci. 55:231-244.

Janzen, H. H. 2011. What place for livestock on a re-greening earth? Anim. Feed Sci. Technol. 166-167:783-796.

Kalof, L., A. Dan, and T. Dietz. 2008. Essentials of Social Research. Open University Press, Berkshire, UK.

Kendall, H. A., L. M. Lobao, and J. S. Sharp. 2006. Public concern with animal well-being: Place, social structural location, and individual experience. Rural Sociol. 71:399-428.

Kilgour, R., and C. Dalton. 1984. Livestock Behavior: A Practical Guide. Granada Publishing Ltd., London, UK.

Knight, S., and L. Barnett. 2008. Justifying attitudes toward animal use: A qualitative study of people's views and beliefs. Anthrozoos 21:31-42.

Knight, S., K. Nunkoosing, A. Vrij, and J. Cherryman. 2003. Using grounded theory to examine people's attitudes toward how animals are used. Soc. Anim. 11:307-327.

Krohn, C., J. Foldager, and L. Mogensen. 1999. Long-term effect of colostrum feeding methods on behavior in female dairy calves. Acta Agric. Scand. A Anim. Sci. 49:57-64.

Krohn, C., B. Jonasen, and L. Munksgaard. 1990. Cow-calf relations. 2: The effect of 0 vs. 5 days suckling on behavior, milk production and udder health of cows in different stabling. Report No. 678. National Institute of Animal Science, Foulum, Denmark.

Krohn, C. C. 2001. Effects of different suckling systems on milk production, udder health, reproduction, calf growth and some behavioral aspects in high producing dairy cows-A review. Appl. Anim. Behav. Sci. 72:271-280.

Lassen, J., P. Sandoe, and B. Forkman. 2006. Happy pigs are dirty! Conflicting perspectives on animal welfare. Livest. Sci. 103:221230

Losinger, W. C., and A. J. Heinrichs. 1997. Management practices associated with high mortality among preweaned dairy heifers. J. Dairy Res. 64:1-11.

Lund, V., S. Hemlin, and J. White. 2004. Natural behavior, animal rights, or making money-A study of Swedish organic farmers' view of animal issues. J. Agric. Environ. Ethics 17:157-179.

Marcé, C., P. Ezanno, H. Seegers, D. U. Pfeiffer, and C. Fourichon. 2011. Within-herd contact structure and transmission of Mycobacterium avium subspecies paratuberculosis in a persistently infected dairy cattle herd. Prev. Vet. Med. 100:116-125.

Maria, G. A. 2006. Public perception of farm animal welfare in Spain. Livest. Sci. 103:250-256.

Metz, J. 1987. Productivity aspects of keeping dairy cow and calf together in the post-partum period. Livest. Prod. Sci. 16:385-394.

Metz, J., and J. Metz. 1986. Maternal influence on defecation and urination in the newborn calf. Appl. Anim. Behav. Sci. 16:325-333. 
Prickett, R. W., F. B. Norwood, and J. L. Lusk. 2010. Consumer preferences for farm animal welfare: Results from a telephone survey of US households. Anim. Welf. 19:335-347.

Rajala, P., and H. Castrén. 1995. Serum immunoglobulin concentrations and health of dairy calves in two management systems from birth to 12 weeks of age. J. Dairy Sci. 78:2737-2744.

Rollin, B. E. 2010. Why is agricultural animal welfare important? The social and ethical context. Pages 21-31 in Improving Animal Welfare: A Practical Approach. T. Grandin, ed. CAB International, Cambridge, MA.

Rowe, G., and L. J. Frewer. 2005. A typology of public engagement mechanisms. Sci. Technol. Human Values 30:251-290.

Rushen, J., A. M. de Passillé, M. A. G. von Keyserlingk, and D. M. Weary. 2008. The Welfare of Cattle. Springer, Dordrecht, the Netherlands.

Schweikhardt, D. B., and W. P. Browne. 2001. Politics by other means: The emergence of a new politic of food in the United States. Rev. Agric. Econ. 23:302-318.

Selman, I. E., A. McEwan, and E. Fisher. 1970. Studies on natural suckling in cattle during the first eight hours post partum. I. Behavioral studies (dams). Anim. Behav. 18:276-283.

Spooner, J. M., C. A. Schuppli, and D. Fraser. 2012. Attitudes of Canadian beef producers toward animal welfare. Anim. Welf. 21:273-283.

Sutherland, M. A., and C. B. Tucker. 2011. The long and short of it: A review of tail docking in farm animals. Appl. Anim. Behav. Sci. 135:179-191.

Svensson, C., K. Lundborg, U. Emanuelson, and S. O. Olsson. 2003. Morbidity in Swedish dairy calves from birth to 90 days of age and individual calf-level risk factors for infectious diseases. Prev. Vet. Med. 58:179-197.

Te Velde, H. T., N. Aarts, and C. Van Woerkum. 2002. Dealing with ambivalence: Farmers' and consumers' perceptions of animal welfare in livestock breeding. J. Agric. Environ. Ethics 15:203-219.
Vanhonacker, F., W. Verbeke, E. Van Poucke, and F. A. M. Tuyttens 2008. Do citizens and farmers interpret the concept of farm anima welfare differently? Livest. Sci. 116:126-136.

Vasseur, E., F. Borderas, R. I. Cue, D. Lefebvre, D. Pellerin, J. Rushen, K. M. Wade, and A. M. de Passillé. 2010. A survey of dairy calf management practices in Canada that affect animal welfare. J. Dairy Sci. 93:1307-1315.

Vetouli, T., V. Lund, and B. Kauffmann. 2012. Farmers' attitudes toward animal welfare aspects and their practice in organic dairy calf rearing: A case study in selected Nordic farms. J. Agric. Environ. Ethics 25:349-364.

Vitale, A. F., M. Tenucci, M. Papino, and S. Lovari. 1986. Social behavior of the calves of semi-wild Maremma cattle, Bos primigenius taurus. Appl. Anim. Behav. Sci. 16:217-231.

von Keyserlingk, M. A. G., and D. M. Weary. 2007. Maternal behaviour in cattle. Horm. Behav. 52:106-113.

Weary, D. M., and B. Chua. 2000. Effects of early separation on the dairy cow and calf. 1: Separation at $6 \mathrm{~h}, 1$ day and 4 days after birth. Appl. Anim. Behav. Sci. 69:177-188.

Weary, D. M., C. A. Schuppli, B. A. Ventura, and M. A. G. von Keyserlingk. 2012. Attitudes to contentious practices in dairy farming. WCDS Adv. Dairy Technol. 24:371-382.

Weary, D. M., C. A. Schuppli, and M. A. G. von Keyserlingk. 2011. Tail docking dairy cattle: Responses from an online engagement. J. Anim. Sci. 89:3831-3837.

Webster, A. J. F., C. Saville, B. M. Church, A. Gnanasakthy, and R. Moss. 1985. Some effects of different rearing systems on health, cleanliness and injury in calves. Br. Vet. J. 141:472-483.

Wesselink, R., K. J. Stafford, D. J. Mellor, S. Todd, and N. G. Gregory. 1999. Colostrum intake by dairy calves. N. Z. Vet. J. 47:31-34. 